\title{
PREVISIÓN DE ERRORES DE SERBIOHABLANTES EN ORACIONES CONDICIONALES Y CONCESIVAS EN ELE: UN ENFOQUE CONTRASTIVO
}

El acercamiento contrastivo a las oraciones condicionales y concesivas que se presenta en este trabajo persigue un objetivo claramente didáctico: identificar las dificultades que pueden tener los aprendientes de ELE serbiohablantes en estos aspectos y buscar sus causas para ayudar a prevenir y superar los errores. El contraste de las estructuras españolas y serbias que se lleva a cabo puede tener una aplicación directa en el trabajo en el aula y en la creación de materiales didácticos, y debe servir para dirigir la atención al tratamiento de las áreas problemáticas y de los errores que ofrecen mayor resistencia.

Las oraciones subordinadas condicionales y concesivas en español plantean dos dificultades formales básicas: el uso de los nexos (sobre todo, los distintos a si y aunque) y la selección de los tiempos y modos verbales (valores referenciales y correspondencia de tiempos). Además de estas cuestiones formales, no se deben olvidar los problemas semánticos y pragmáticos que conllevan las implicaciones presentes en ellas.

Esta aproximación a estructuras complejas supone una llamada de atención sobre los errores de aprendientes competentes que, dado que no suelen dificultar la comunicación, pasan inadvertidos y/o no se proponen terapias específicas para superarlos, lo que puede dar lugar a la fosilización.

Palabras clave: Aprendizaje de ELE, serbiohablantes, oraciones condicionales y concesivas, análisis contrastivo, previsión de errores, implicaciones didácticas.

\section{Introducción}

Ya se han llevado a cabo algunas investigaciones, aunque todavía escasas, en el campo del análisis de errores de serbiohablantes en ELE (Santos Gargallo 1991, 1993, 1994; García González y Alonso Zarza, 2009; Krstić y Pištignat 2013; Zečević Krneta 2013; Rubinjoni Strugar 2014), en 
las que se destacan, sobre todo, los efectos negativos de la L1 en el aprendizaje de ELE, especialmente, en el uso los artículos y de los tiempos verbales. El estudio de estructuras complejas ha quedado, sin embargo, fuera del centro de interés de los investigadores, por lo que creemos que es necesario dirigir la atención hacia este tipo de construcciones, presentes en la actuación de aprendientes autónomos y competentes.

A pesar de que todos estos trabajos subrayan la transferencia de la L1 en las producciones en español de serbiohablantes, no se ha publicado todavía ningún contraste sistemático entre estructuras sintácticas complejas de ambas lenguas que ayude a prever posibles errores en la actuación de estos aprendientes, y a dirigir los esfuerzos en la enseñanza hacia aquellas cuestiones que puedan resultar más arduas de aprender.

Por ello, nos acercaremos en primer lugar a las oraciones condicionales y concesivas en serbio para presentar una visión general del sistema, basada en algunas de las gramáticas de referencia (Barić et al. 1979; Stevanović 1989; Stanojčić y Popović 1992; Klajn 2005) que pueda servir para contrastarlas con las del español ${ }^{2}$. Teniendo en cuenta que el acceso a las descripciones gramaticales de esta lengua es todavía muy limitado, creemos que este apartado puede resultar muy útil para los profesores e investigadores de ELE no conocedores de la lengua serbia que trabajen con serbiohablantes. Asimismo, supone también una valiosa herramienta para aquellos que son hablantes nativos de serbio, puesto que ofrece la posibilidad de observar su propia lengua y, en muchos casos, de tomar conciencia de algunos hechos del funcionamiento de su propia lengua que, precisamente por eso, pueden pasárseles inadvertidos.

Después, plantearemos la previsión de errores y las áreas de dificultad en el aprendizaje de estas oraciones utilizando en el contraste de algunas estructuras en las dos lenguas, y advirtiendo tanto similitudes como diferencias que pueden favorecer u obstaculizar su adquisición.

Como podremos observar, solo una parte de los posibles errores en estas estructuras serán exclusivos de éstas, mientras que otros podrán apa-

2 Para una descripción detallada de las oraciones condicionales y concesivas en español puede verse Flamenco García 1999, López García 1999; Montolío 1999 y RAE 2009; así como materiales de ELE como Montolío 1993; Matte Bon 1995; Pastor Cesteros 1999; Fernández Molero et al. 2004; Instituto Cervantes 2006 y Llopis-García et al. 2012. 
PREVISIÓN DE ERRORES DE SERBIOHABLANTES EN ORACIONES CONDICIONALES Y CONCESIVAS...

recer en cualquier actuación en español de los serbiohablantes. Los primeros estarán relacionados con el uso de los nexos condicionales y concesivos (forma y significado), con las restricciones que imponen en la selección de las formas verbales (tiempo y modo) y, sobre todo, con los diferentes significados que pueden expresar según las relaciones que se establecen entre los dos miembros de estas oraciones, basadas no solo en la selección del nexo y de las formas verbales, sino también otros elementos contextuales. Los segundos afectarán a categorías como la determinación (uso de los artículos) o las referencias temporales (uso de los tiempos de pasado).

También comprobaremos que la transferencia de la L1 puede ser tanto positiva como negativa y que no es el único factor que puede dificultar el uso adecuado de estas estructuras, es decir, que también se producirán errores intralinguales, debidos a las características de estas estructuras en español, o errores por transferencia de instrucción, debidos a la forma en la que se enseñan.

Por último, considerando que el objetivo de este trabajo es didáctico, se muestran las implicaciones didácticas del mismo. En este sentido, se defiende que para lograr el dominio de las oraciones condicionales y concesivas es necesaria una instrucción especifica centrada, tanto en la atención a la forma, a la estructura sintáctica y a los elementos que son parte de ella, como en los significados que transmiten contando con elementos semánticos, pragmáticos y discursivos imprescindibles para su adecuada comprensión y producción.

\section{Las oraciones condicionales y concesivas en serbio}

\subsection{Características generales}

Las oraciones condicionales y concesivas cierran la lista de oraciones subordinadas que ofrece Stevanović (1989 779-915) ${ }^{3}$. Excepto la distinción entre coordinadas y subordinadas, este autor no establece ninguna clasificación de las oraciones compuestas y se limita a presentar una sucesión de tipos, definidos con criterios muy variados y poco uniformes.

3 El texto de Stevanović, Savremeni srpskohrvatski jezik (La lengua serbiocroata actual), cuya primera edición apareció en 1975 (aquí se cita la edición de 1989), pese a sus limitaciones, sigue siendo punto de partida y referencia obligada. 
Como muestra, estas son las clases de oraciones subordinadas que describe y el orden en el que lo hace: declarativas, volitivas, imperativas, desiderativas, interrogativas indirectas, finales, relativas, temporales, de lugar, comparativas y modales, causales, consecutivas, condicionales y concesivas. En esta lista, además de la ausencia de criterio, llama la atención el análisis de las comparativas y modales como un mismo tipo ${ }^{4}$.

Por el contrario, Stanojčić y Popović (1992), siguiendo la tradición gramatical, dividen las oraciones subordinadas en tres tipos, sustantivas, adjetivas y adverbiales, e incluyen las oraciones condicionales y concesivas dentro de las últimas.

En general, las condicionales y las concesivas en serbio muestran valores expresivos muy similares a los del español y coinciden en muchas de sus propiedades ${ }^{5}$. Aunque con diferencias en las restricciones que aparecen en cada caso, admiten la elipsis en sus miembros $(1,2)$, prótasis truncadas o suspendidas $(3,4)$, apódosis formadas por imperativos $(5)$, interrogativas o exclamativas (6), las prótasis pueden ser focalizadas $(7,8)$, pueden establecer relaciones más allá del marco oracional e incluso textual $(9,10)$, etc., como muestran los siguientes ejemplos ${ }^{6}$ :

1) Ako ona ide, i ja ću.

'Si ella va, yo también'

2) lako će ona ići, ja neću.

'Aunque ella vaya/irá, yo no'

3) Ako bi znao...

'Si supiera...'

4) I da mogu...

'Aunque pudiera...'

5) Zatvorite vrata ako Vam je hladno.

'Cierre la puerta si tiene frío'

4 Barić et al. (1979) y Stanojčić y Popović (1992) también las analizan como un mismo tipo.

$5 \quad$ No es nuestro objetivo llevar a cabo un análisis detallado de este tipo de oraciones, sino presentar someramente su estructura para ofrecer una visión general del sistema (dejando al margen excepciones y formas menos frecuentes) que pueda ayudar a contrastarlas con el español.

6 La traducción o traducciones que se proponen en este trabajo para los ejemplos en serbio son las más aproximadas, pero no las únicas. En contextos más específicos se podrían ofrecer otras traducciones más adecuadas. 
PREVISIÓN DE ERRORES DE SERBIOHABLANTES EN ORACIONES CONDICIONALES Y CONCESIVAS...

6) Šta će reći tvoj žena, ako sazna?

'¿Qué dirá tu mujer si se entera?'

7) Ako mu nešto smeta, to je da mora da ustaje rano

'Si algo le molesta es tener que madrugar'

8) Čak iako hoćeš da mi pomogneš, ne možeš.

'Incluso aunque quieras ayudarme, no puedes.'

9) Ako Vam ne smeta, sedite, molim Vas na drugo mesto.

'Si no le molesta, siéntese, por favor, en otro sitio'

10) lako ne veruješ, otišli su na odmor.

'Aunque no te lo creas, se han ido de vacaciones'

También coinciden con el español en el orden prótasis-apódosis como no marcado, que supone la presentación de la información de la prótasis como información temática y la de la apódosis como remática. No obstante, debido a factores discursivos este orden se puede alterar como muestran los siguientes ejemplos:

11) Majka ga neće grditi ako uradi (bude uradio) domaći.

'Su madre no le regañará si hace los deberes'

12) Zalutao je iako je znao put.

'Se perdió aunque conocía el camino'

\subsection{Las oraciones condicionales}

Las conjunciones más frecuentes que se utilizan en las oraciones condicionales son ako, da, ukoliko y kad; todas ellas en su valor condicional introducen oraciones equivalentes a las del español introducidas por si; además se puede usar la partícula li pospuesta al verbo. De ellas, ako 'si'y ukoliko 'si, en la medida de que' se usan solo como conjunciones condicionales, mientras que kad 'si, cuando', es básicamente una conjunción temporal que puede aparecer también en otros tipos de subordinadas y da es multifuncional y está presente en muchas estructuras subordinadas (su uso podría equipararse al de que en español). Como veremos, la conjunción y la forma verbal de la prótasis determinan el valor de la oración condicional e imponen las restricciones a la forma verbal que puede aparecer en la apódosis. 
Stanojčić y Popović (1992: 311-314)7 basan su clasificación de las condicionales en dos criterios: la realización de la condición y el tiempo al que se refiere la condición. Atendiendo al primer criterio se distinguen: reales, potenciales e irreales. Según el segundo, la condición puede ser: de futuro, de presente, de pasado y universal. Al margen de estos dos criterios, no señalan nada más sobre los valores, usos y restricciones de estas oraciones, ni tampoco mencionan otro tipo de condicionales introducidas por otras conjunciones o locuciones ${ }^{8}$.

En la siguiente tabla se esquematizan los tipos de condicionales más frecuentes, equivalentes a las introducidas por si en español:

\begin{tabular}{|c|c|c|c|c|c|}
\hline \multicolumn{6}{|c|}{ ORACIONES CONDICIONALES } \\
\hline $\begin{array}{l}\text { TIPO DE } \\
\text { CONDICIÓN }\end{array}$ & $\begin{array}{l}\text { TIEMPO DE LA } \\
\text { CONDICIÓN }\end{array}$ & CONJUNCIÓN & $\begin{array}{l}\text { FORMA VERBAL } \\
\text { DE LA PRÓTASIS }\end{array}$ & $\begin{array}{l}\text { FORMA VERBAL } \\
\text { DE LA APÓDOSIS }\end{array}$ & EJEMPLOS \\
\hline 1. Real & Futuro & $\begin{array}{l}\text { ako } \\
\text { ukoliko } o^{(1)} \\
\text { li }\end{array}$ & $\begin{array}{l}\text { Presente } \\
\text { Futuro II }\end{array}$ & $\begin{array}{l}\text { Futuro I } \\
\text { Imperativo }\end{array}$ & $\begin{array}{l}\text { Ako se potrudite/budete potrudili, uspećete. } \\
\text { 'Si os esforzáis, lo lograréis' } \\
\text { Ako prolazišbudeš prolazio tamo, kupi novine. } \\
\text { 'Si pasas por alli, compra el periódico' } \\
\text { Potrudiš li se, uspećeš } \\
\text { 'Si te esfuerzas, lo lograrás' }\end{array}$ \\
\hline 2. Real & Presente & $\begin{array}{l}\text { ako } \\
\text { ukoliko } \\
\text { (1) }^{2}\end{array}$ & $\begin{array}{l}\text { Presente } \\
\text { Perfecto }\end{array}$ & $\begin{array}{l}\text { Futuro I } \\
\text { Imperativo }\end{array}$ & $\begin{array}{l}\text { Ako je Marko u školi, preneću mu poruku } \\
\text { 'Si Marko está en la escuela, le daré el recado' } \\
\text { Ako je Marko stigao u školu, prenesi mu poruku. } \\
\text { 'Si Marko ha llegado a la escuela, dale el recado' }\end{array}$ \\
\hline 3. Real & Universal & $\begin{array}{l}\text { ako }^{(1)} \\
\text { ukoliko }^{(1)}\end{array}$ & Presente & Presente & $\begin{array}{l}\text { Ako se gvoždje zagreva, širi se. } \\
\text { 'Si el hierro se calienta, se dilata' }\end{array}$ \\
\hline 4. Potencial & Futuro & $\begin{array}{l}\mathrm{kad}+(\mathrm{a}) \\
\mathrm{da}+\text { (b) }\end{array}$ & $\begin{array}{l}\text { (a) Potencial } \\
\text { (b) Presente }\end{array}$ & Potencial & $\begin{array}{l}\text { Kad biste se potrudili, uspeli biste. } \\
\text { 'Si os esforzarais, lo lograriais' } \\
\text { Da se potrudite, uspeli biste. } \\
\text { 'Si os esforzarais, lo lograriais' }\end{array}$ \\
\hline 5. Irreal & Presente & $\begin{array}{l}k a d+(a) \\
d a+(b)\end{array}$ & $\begin{array}{l}\text { (a) Potencial } \\
\text { (b) Presente }\end{array}$ & Potencial & $\begin{array}{l}\text { Kad bih imao vremena, bavio bih se sportom. } \\
\text { 'Si tuviera tiempo, me dedicaría al deporte' } \\
\text { Da se trudite, postizali biste bolje rezultate. } \\
\text { 'Si os esforzarais, lograríais mejores resultados' }\end{array}$ \\
\hline 6. Irreal & Pasado & $d a$ & Perfecto & $\begin{array}{l}\text { Potencial I } \\
\text { Potencial II } \\
\text { (2) }\end{array}$ & $\begin{array}{l}\text { Da ste im pisali, oni bi se radovali. } \\
\text { 'Si les hubierais escrito, se habrían alegrado' } \\
\text { Da ste im pisali, oni bi se bili radovali. } \\
\text { 'Si les hubierais escrito, se habrían alegrado' }\end{array}$ \\
\hline
\end{tabular}

7 Seguimos esta clasificación ya que describe más adecuadamente la estructura de las condicionales y resulta más clara para los no hablantes de serbio. Además de los tipos de oraciones compuestas que vamos a describir, los más frecuentes, existen otras construcciones para expresar condición, que por su especificidad semántica o estructural, no presentaremos aquí.

8 En general, las gramáticas (Barić et al. 1979; Stevanović 1989; Stanojčić y Popović 1992, Klajn, 2005) se limitan a establecer los tipos y a presentar una lista de ejemplos de las estructuras que se consideran prototípicas. No se mencionan valores semánticos específicos, ni restricciones formales, semánticas o pragmáticas, ni otras formas de expresar condición. 
PREVISIÓN DE ERRORES DE SERBIOHABLANTES EN ORACIONES CONDICIONALES Y CONCESIVAS...

En general, las condicionales reales (tipos 1, 2, y 3 de la tabla) van introducidas por la conjunción ako (son equivalentes al tipo "si + indicativo" en español), las potenciales (tipo 4) por kad (son equivalentes al tipo "si + imperfecto de subjuntivo") y las irreales (tipos 5 y 6) por da (son equivalentes al tipo "si + imperfecto o pluscuamperfecto de subjuntivo").

Estos autores incluyen como ejemplo de condición real referida al presente (tipo 2) un caso cuya prótasis se refiere claramente al pasado (es la apódosis la que se refiere al presente): Ako je Marko stigao u školu, prenesi mu poruku ('Si Marko ha llegado a la escuela, dale el recado'). Es decir, se trata de una condición real, pero no de presente, sino de pasado como demuestra el uso del perfecto ${ }^{9}$ (perfekat), la forma de pasado no marcada. A pesar de que no se recoge ningún caso en las gramáticas consultadas, es posible también en el periodo real que tanto prótasis como apódosis aludan al pasado, en cuyo caso ambas formas verbales se usan en perfecto: Ako si bio u Granadi, verovatno si video Alhambru ('Si estuviste en Granada seguro que viste la Alhambra'). El presente en las prótasis reales puede interpretarse como presente actual, habitual o universal (tipo 2 y 3) o como prospectivo (tipo 1).

Las prótasis potenciales pueden estar introducidas por las conjunciones kad o da pero cada una de ellas impone distintas restricciones sobre la forma verbal: kad requiere un potencial (potencijal), mientras $d a$ exige un presente. Además, las introducidas por da suelen estar orientadas al presente actual, mientras que las introducidas por kad pueden referirse a un presente universal o al futuro. La interpretación del periodo potencial suele ser contrafactual (13), pero no se excluye la factual (14) en determinados contextos:

13) Da vidim dobro, ne bih nosila naočare / Kad bih videla dobro, ne bih nosila naočare. 'Si viera bien, no llevaría gafas'

14) Da je tu četiri, ovde bi bilo šest.

(Haciendo un sudoku) 'Si ahí hay un cuatro, aquí habría un 6'

Estos autores consideran periodo potencial únicamente a aquel cuya condición se establece como posible en el futuro (tipo 4) e incluyen

9 El sistema verbal consta de varios tiempos de pasado (perfekat, imperfekat, pluskvamperfekat y aorist), pero en la lengua estándar actual solo se utiliza uno como pasado no marcado, el perfecto (perfekat). 
dentro del periodo irreal aquellas con una condición de interpretación contrafactual en el presente (tipo 5). La comparación entre los tipos 4 y 5 muestra que tienen una estructura similar, ya que ambos admiten las construcciones "kad + potencial" y " $d a+$ presente" (en español se corresponderían con una estructura de "si+ imperfecto de subjuntivo, condicional simple"). No obstante, el tipo 4 expresa una condición que no se da en el presente, pero que se considera posible en el futuro: Kad biste se trudili, uspeli biste, 'Si os esforzarais, lo lograríais' (con la interpretación 'ahora no os esforzáis, pero en el caso de que en el futuro sí os esforcéis, puede ser que lo logréis'); mientras que el tipo 5 presenta una condición en la que lo más relevante es que no se verifica en el presente: Kad bih imao vremena, bavio bih se sportom, 'Si tuviera tiempo, haría deporte' (con la interpretación 'no hago deporte porque no tengo tiempo').

El tipo 6 equivale a las condicionales de "si + pluscuamperfecto de subjuntivo, condicional compuesto/pluscuamperfecto de subjuntivo". De todas las estructuras condicionales es la que mantiene un esquema más estricto, en el sentido de que la prótasis está formada siempre por el nexo da y un verbo en perfecto (el tiempo pasado no marcado). En la apódosis puede aparecer tanto un potencial segundo (equivalente al condicional compuesto), como un potencial primero (equivalente al condicional simple). Las condicionales irreales de este tipo tienen siempre una interpretación contrafactual, es decir, de ellas se infiere lo contrario de lo que se expresa: Da ste im pisali, oni bi se radovali ('Si les hubierais escrito, se habrían alegrado' implica que 'no les escribieron' y que 'no se alegraron').

La conjunción ukoliko (formada por la preposición $u$ 'en' y el cuantificador koliko 'cuanto') puede introducir prótasis reales con un valor de requisito más fuerte que $a k o$, así que admitiría la paráfrasis con siempre que, siempre y cuando o con tal de que.

En cuanto a la partícula li, se usa siempre en prótasis con presente. Dada su naturaleza clítica y que en serbio los clíticos ocupan necesariamente la segunda posición en una oración o periodo, la prótasis se inicia siempre con la forma verbal seguida de li:

15) Majka će ti oprostiti zamoliš li je za oproštenje.

'Tu madre te perdonará si le pides perdón' 
PREVISIÓN DE ERRORES DE SERBIOHABLANTES EN ORACIONES CONDICIONALES Y CONCESIVAS...

Existen además algunas locuciones conjuntivas que pueden introducir valores condicionales como las formadas con algunos sustantivos como uslov 'condición' o slučaj 'caso', pod uslovom da 'con la condición de (que)' y u slučaju 'en el caso de (que)':

16) Daću ti to pod uslovom da mi ga vratiš sutra.

'Te lo doy con la condición de que me lo devuelvas mañana'

17) U slučaju da ga budeš video, kaži mu da me nazove.

'En el caso de que le veas, dile que me llame'

Para terminar este repaso de las oraciones condicionales más frecuentes, algunos gerundios, como pretpostavljajući 'suponiendo', también pueden formar prótasis condicionales:

18) Pretpostavljajući da ljudi zaista počnu da koriste ovu funkciju, krađa smartfona i tableta bi trebalo da se smanji drastično, jer... ${ }^{10}$

'Suponiendo que la gente de verdad utilice esa función, los robos de smartphone y tabletas deberían reducirse drásticamente, porque...'

\subsection{Oraciones concesivas}

Las conjunciones con claro valor concesivo son iako, mada, premda, i kad, i da, ako i, neka i, ma y makar ${ }^{11}$. lako es la menos marcada y más frecuente, y en las construcciones equivalentes a las del español de "aunque + indicativo", alterna con mada y premda sin que el uso de una conjunción u otra suponga variaciones semánticas significativas.

Si tomamos las concesivas con iako, i kad, i da y ako i como prototípicas, podremos observar que las estructuras son paralelas a las de las condicionales con $a k o, k a d$ y da y que las conjunciones concesivas se pueden descomponer en $i$ (' $y$ ' conjunción copulativa) y ako, kad y da conjunciones que también introducen prótasis condicionales.

10 Ejemplo tomado de http://www.telegraf.rs/hi-tech/1270266-evo-sta-ce-spasitivas-android-od-kradje [web 28.8.2016].

11 Ma y makar (procedente del griego bizantino makari 'ojalá', está etimológicamente relacionada con la española maguer) tienen ciertas particularidades sintácticas y semánticas, además de estilísticas, en las que no nos vamos a detener como, por ejemplo, que formalmente exigen el verbo en perfecto truncado (sin el verbo auxiliar) y, semánticamente, el obstáculo que se presenta para la realización de la acción de la oración principal es siempre una suposición o hipótesis que se percibe como irrealizable. 
De la misma manera que ocurre en las oraciones condicionales, en las concesivas es el nexo, junto con la forma verbal de la prótasis, el que impone las restricciones sobre el verbo de la apódosis e informa sobre el tipo de concesión que se quiere expresar.

En la siguiente tabla recogemos la estructura de las oraciones concesivas más frecuentes, equivalentes a las introducidas por aunque en español, siguiendo un esquema similar al propuesto para las condicionales, con el objeto de destacar su similitud estructural ${ }^{12}$. En él se distinguen concesivas reales, potenciales e irreales, sin diferenciar entre hipotéticas y factuales y sin tener en cuenta otros factores ${ }^{13}$.

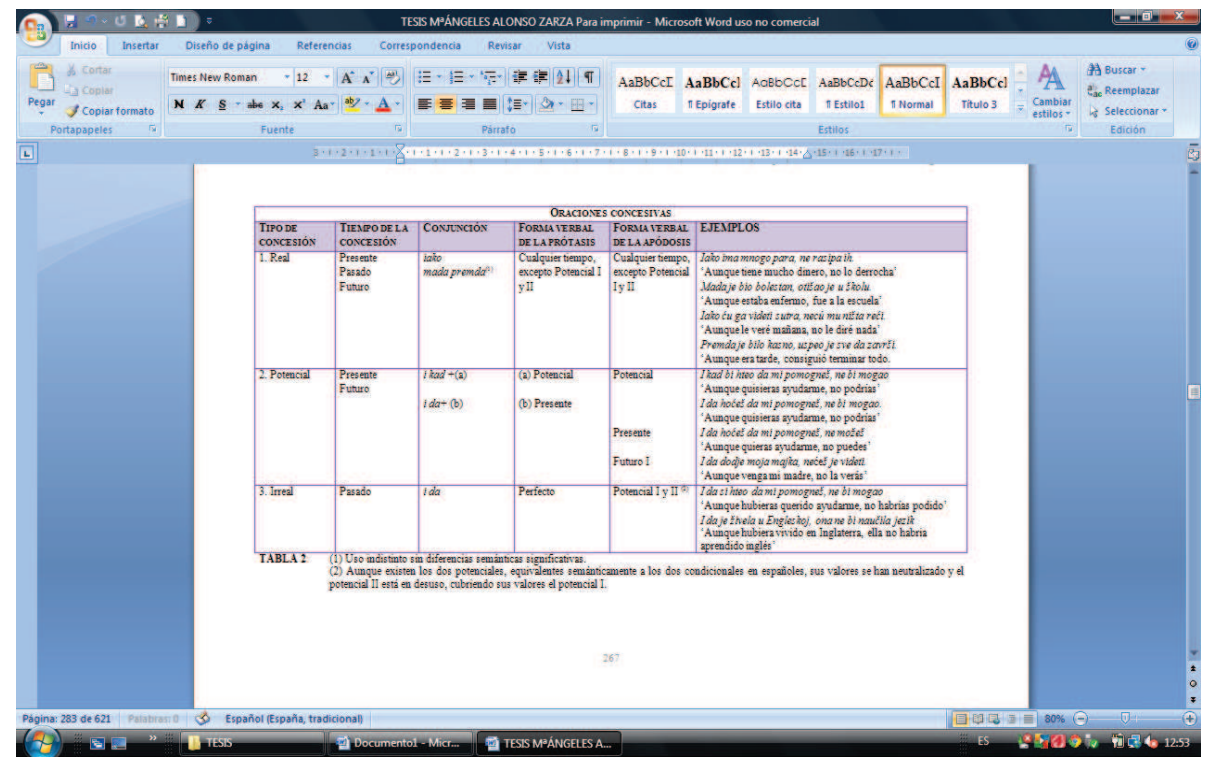

En las concesivas reales (tipo 1 de la tabla) la prótasis se interpreta como factual, es decir, describen una situación existente que no supone un

12 El esquema que refleja la tabla debe ser observado con precaución, debido a sus limitaciones. Sin embargo, nos parece que puede resultar útil para describir tres tipos de estructuras características (Barićet al. 1979: 420-422; Stanojčić y Popović 1992: 315-316).

13 Puede verse un planteamiento con consideraciones semánticas y pragmáticas sobre las oraciones concesivas en croata y serbio en Pranjković (2001), Kovačević (2008), entre otros. 
PREVISIÓN DE ERRORES DE SERBIOHABLANTES EN ORACIONES CONDICIONALES Y CONCESIVAS...

obstáculo para el cumplimiento de la acción de la apódosis y, además se presenta este impedimento como una información nueva. Son equivalentes a las del español introducidas por aunque y con la forma verbal en indicativo.

Las prótasis del tipo 2, potenciales, son hipotéticas y pueden referirse a una situación actual o futura. Cuando se refieren al presente generalmente se interpretan como contrafactuales, ya que se infiere que la situación no se da en ese momento. Las conjunciones imponen ciertas restricciones sobre las formas verbales que pueden aparecer. I kad exige el potencial tanto en la prótasis como en la apódosis, ya sea una oración de interpretación actual, como prospectiva. I da selecciona una forma verbal en presente en la prótasis y acepta potencial, presente y futuro primero (futur prvi, equivalente al futuro de indicativo en español) en la apódosis.

Las concesivas irreales, tipo 3, se refieren al pasado y tienen siempre una interpretación contrafactual ya que se infiere lo contrario de lo que se afirma. Así de I da si hteo da mi pomogneš, ne bi mogao ('Aunque hubieras querido ayudarme, no habrías podido') se infiere que nisi hteo ('no quisiste') y que nisi mogao da mi pomogneš ('no pudiste ayudarme'). Estas prótasis introducidas por $i$ da se forman con el verbo en perfecto y en la apódosis puede aparecer cualquiera de los dos potenciales (consecuencia de la neutralización de las diferencias entre ambos en el uso).

En las prótasis reales factuales en las que se presenta la información como conocida o no relevante, no se utiliza la conjunción iako, sino el conector complejo neka i... ali, que puede dar lugar también a oraciones adversativas:

19) Neka i ima mnogo para, ali ih ne rasipa.

'Aunque tenga mucho dinero, no lo derrocha'

'Tendrá mucho dinero, pero no lo derrocha'

Junto con neka i, ako $i$ también suele aparecer en las prótasis factuales, con significado equivalente al del llamado subjuntivo polémico ${ }^{14}$ (RAE 2009: 3608-3609) en español:

14 Es habitual este uso en contextos en los que el hablante retoma un argumento presentado previamente por su interlocutor para invalidarlo por lo que se ha denominado subjuntivo polémico. El carácter temático de estas prótasis permite que el hablante las emplee cuando supone que la información es conocida para su interlocutor o cuando desea presentarla así por motivos discursivos. 
20) - Znaš da će Jovan doći na večeru?

'¿Sabes que Juan va a venir a cenar?'

- E pa meni je rekao da neće (doći).

'Pues a mí me ha dicho que no (viene)'

- Neka ti je i rekao tako/Ako ti je i rekao tako, sigurno će doći

'Pues aunque te haya dicho eso, seguro que viene'

Algunas oraciones con cuantificadores en la prótasis y en la apódosis (toliko 'tanto', jedva 'apenas', malo 'poco', mnogo 'mucho', tako malo 'tan poco', tako mnogo 'tanto', etc.) y con la conjunción copulativa contrastiva a como introductora de esta última tienen valor concesivo de interpretación factual:

21) Toliko radi, a jedva nešto zaradi.

'Con lo que trabaja y apenas gana nada'

22) Tako mnogo radi, a tako malo zarađuje.

'Con lo mucho que trabaja y lo poco que gana'

Otras, con el cuantificador koliko ('cuanto') y la partícula god introducen siempre prótasis hipotéticas:

23) Koliko god da uči, nikad neće položiti.

'Por mucho que estudie, nunca aprobará'

Por último, dada su frecuencia de uso, es necesario mencionar otro grupo, equivalente a las fórmulas duplicadas en español (pase lo que pase, sea quien sea, llame o no llame, etc.). Las prótasis que introducen personas, lugares, tiempos, etc. (parciales) se pueden formar con un interrogativo como šta ('qué'), ko ('quién'), gde (dónde) o kako ('como') y con la partícula god o el participio neutro del verbo biti (bilo):

24) Šta god bilo/da bude, uvek ću biti uz tebe.

'Pase lo que pase, yo siempre estaré a tu lado'

25) Nemoj da mi daš vezu, ko god da je osoba koja me zove.

'No me pases llamadas, sea quien sea la persona que llame'

26) Bilo šta da ti kažu, nemoj da im veruješ.

'Digan lo que digan, no les creas'

Las totales, polares de sí o de no, se construyen con el perfecto truncado y la conjunción disyuntiva ili ('o') y la partícula negativa ne: 
PREVISIÓN DE ERRORES DE SERBIOHABLANTES EN ORACIONES CONDICIONALES Y CONCESIVAS...

27) Hteo ili ne (hteo), moraš da ideš sutra u školu.

'Quieras o no (quieras), tienes que ir al colegio mañana'

28) Imao ili ne imao para, moraće da plati kaznu.

'Tenga o no tenga dinero, tendrá que pagar la multa

\section{Contraste y previsión de errores en ELE}

El contraste de las oraciones condicionales y concesivas en español y en serbio nos permitirá predecir no solo errores interlinguales, debidos a la transferencia de la L1, sino también errores intralinguales, debidos a la complejidad de las estructuras en español o de sus valores. Asimismo, se podrá observar qué cuestiones no presentan a priori dificultades para los aprendientes.

La expresión de la condición y de la concesión comprende una amplísima gama de matices semántico-pragmáticos y un conjunto muy rico de estructuras sintácticas que pueden usarse en contextos comunicativos muy distintos, por lo que se hace necesario acotar las estructuras contrastadas. Para ello, se ha tomado como referencia el inventario que ofrece el Plan Curricular del Instituto Cervantes. Niveles de referencia ${ }^{15}$ (2006), así como otros manuales y materiales de ELE (García Santos 1992; Matte Bon 1992; Coronado González et al. 1996, 2003, 2004; Chamorro Guerrero et al. 2006, 2010; Gómez Torrego 2007; Martí et al. 2009; Palencia y Aragonés 2009, 2010; Alonso Raya et al. 2011; Llopis-García et al. 2012; Castañeda (coord.) 2014) y se han seleccionado las más frecuentes ${ }^{16}$.

A continuación se mostrarán en cada apartado algunos ejemplos de oraciones en español y su equivalente en serbio para ilustrar el contraste de estas en las dos lenguas y después se formulan algunas hipótesis sobre los errores que pueden aparecer en las producciones de los hablantes de serbio aprendientes de español. La previsión de errores se plantea sobre la presunción de que los aprendientes tienen un nivel de dominio de la

15 En adelante $P C I C$.

16 Por limitaciones de espacio, no se presentan, por ejemplo, algunas, aunque se recogen en el inventario de los Niveles de referencia del $P C I C$, del tipo Atrévete a hacerlo y verás o Que te apetece, te vas, que no te apetece, te quedas, u otras propias de lenguajes específicos, como las que contienen el futuro de subjuntivo ( $\mathrm{Si}$ hubiere una disposición contraria...). 
lengua en el que ya conocen estas oraciones, por lo que se mencionará en qué nivel aparece cada una en los Niveles de referencia del PCIC.

\subsection{Oraciones condicionales}

\subsubsection{Prótasis introducidas por si}

\subsubsection{Reales (condiciones posibles referidas al pasado, presente} y futuro)

29) Si pasas por allí, compra el periódico ${ }^{17}$.

Ako prođeš tuda, kupi novine ${ }^{18}$.

[Prót.: Ako + pres. / Apód.: imp.] ${ }^{19}$

17 La mayoría de los ejemplos en español se han tomado de M. L. Coronado González et al. (1996: 99-111).

18 En las oraciones en serbio se marcan con un subrayado los nexos y las formas verbales. Por lo que se refiere a los tiempos compuestos (perfecto, futuro II, condicional I y condicional II), formados con el auxiliar del verbo biti y el participio pasivo del verbo, hay que señalar que ambos componentes de la forma verbal pueden aparecer separados, es decir, puede haber algunos elementos oracionales (sobre todo, pronombres y adverbios) entre el auxiliar y el participio y también puede anteponerse el participio al auxiliar debido a determinadas restricciones sobre el orden oracional.

19 Se presenta entre corchetes el esquema formal de las estructuras en serbio. Abreviaturas empleadas:

Prót. prótasis

Apód. apódosis

pres. presente

perf. perfecto (pasado no marcado, según el contexto, puede equivaler a cualquier tiempo de pasado del español)

fut. I futuro primero (tiempo no marcado de futuro, equivalente al futuro imperfecto de indicativo)

fut. II futuro segundo (forma verbal de marcado carácter modal con valor de futuro, equivalente, en ocasiones, al presente de subjuntivo)

cond. I condicional primero (equivalente al condicional simple del español, sus valores y usos se han ampliado hasta abarcar también los propios del condicional segundo)

cond. II condicional segundo (equivalente al condicional compuesto del español, cuyo uso está quedando relegado a la lengua escrita culta y sus valores han sido asumidos por el condicional primero en la lengua estándar)

imp. imperativo 
PREVISIÓN DE ERRORES DE SERBIOHABLANTES EN ORACIONES CONDICIONALES Y CONCESIVAS...

Ako budeš prolazio tuda, kupi novine.

[Prót.: Ako + fut. II / Apód.: imp.]

30) Si estuviste en Granada, seguro que viste la Alhambra, ¿no?

Ako si bio u Granadi, verovatno si video Alhambru, zar ne?

[Prót.: Ako + perf. / Apód.: perf.]

31) Si estaba en casa, ¿por qué ha dicho que no estaba?

Ako je bio kod kuće, zašto je rekao da nije bio?

[Prót.: Ako + perf. / Apód.: perf.]

32) Si me entero, te llamo enseguida, no te preocupes.

Ako saznam, zvaću te odmah, ne brini.

[Prót.: Ako + pres. / Apód.: fut. I]

Ako budem saznala, zvaću te odmah, ne brini.

[Prót.: Ako + fut. II / Apód.: fut. I]

Ako saznam, zovem ${ }^{20}$ te odmah, ne brini.

[Prót.: Ako + pres. / Apód.: pres.]

Este tipo de oraciones son las primeras condicionales con las que se encuentran los aprendientes de ELE. Según el $P C I C$ se estudian desde el nivel A2 hasta el B2 con la siguiente progresión:

- Nivel A2: condicionales con la prótasis y la apódosis en presente de indicativo.

- $\quad$ Nivel B1: condicionales con prótasis en presente de indicativo y apódosis con futuro imperfecto o imperativo.

- Nivel B2: condicionales con prótasis con todos los tiempos de indicativo (excepto futuro) y apódosis con todos los tiempos de indicativo.

Dada la similitud de las estructuras y los significados de estas oraciones en una y otra lengua, este tipo de condicionales no representan $a$ priori un área de dificultad para los serbiohablantes; el único problema puede surgir en la elección de las formas verbales que contienen.

En las oraciones con si condicional con presente de indicativo podría aparecer el presente de subjuntivo, ya que en serbio algunos de los valores de futuro que expresa el presente de indicativo y la mayoría de los del

El uso del presente en la apódosis es propio de un registro muy coloquial. 
presente de subjuntivo pueden ser expresados por el denominado futuro II, que los estudiantes tienden a identificar con el presente de subjuntivo.

Si la oración se refiere al pasado, tanto en la subordinada como en la principal, puede haber una selección errónea del tiempo verbal. Estos errores pueden deberse a tres tipos de cuestiones:

- La transferencia de la L1, ya que el perfecto, tiempo de uso general para referirse al pasado, carece de información temporal precisa;

- La complejidad de los valores y usos de los diferentes tiempos verbales en español;

- El hecho de que en los materiales de ELE sea mucho más frecuente la aparición de las condicionales reales referidas al presente y al futuro que al pasado;

Así, los estudiantes pueden tener dificultades para identificar las referencias y las relaciones temporales implicadas y, por tanto, para seleccionar el tiempo verbal adecuado.

\subsubsection{Potenciales (condiciones que no son reales en el presente o son improbables en el futuro)}

33) Si les escribierais, se alegrarían.

Kad biste im pisali, oni bi se radovali.

[Prót.: Kad + cond. I / Apód.: cond. I]

34) Si por casualidad llamara mi madre, dile que mañana iré a verla.

Ako bi slučajno zvala moja majka, kaži joj da ću sutra ići da je vidim. [Prót.: Ako + cond. l/ Apód.: imp.]

35) Si tuviera lo que tú tienes, yo ya habría dejado el trabajo.

Kad bih imala ono što ti imaš, već bih ostavila posao.

[Prót.: Kad + cond. I / Apód.: cond. I]

Da imam ono što ti imaš, već bih ostavila posao.

[Prót.: $D a+$ pres. / Apód.: cond. I]

36) Si pudiera, ahora mismo me iba.

$\underline{\text { Kad bih mogao, sada bih odmah otišao. }}$

[Prót.: Kad + cond. I/ Apód.: cond. I]

Da mogu, sada bih odmah otišao.

[Prót.: $D a+$ pres. / Apód: cond. I] 
PREVISIÓN DE ERRORES DE SERBIOHABLANTES EN ORACIONES CONDICIONALES Y CONCESIVAS...

37) Si acaso la vieras, dale un beso de mi parte.

Ako bi je slučajno video, poljubi je za mene.

[Prót.: Ako + cond. I / Apód: imp.]

38) Si algún día llega a enterarse el jefe de eso, nos mata.

Ako jednog dana šef sazna za to, ubiće nas.

[Prót.: Ako + pres. / Apód.: fut. I]

Según el $P C I C$ el estudio de las condicionales potenciales se inicia en el nivel B2. En este nivel se presenta la estructura tipo Si tuviera tiempo, te ayudaría, mientras que las que incluyen alguna forma de indicativo o el imperativo, se tratan en los niveles $\mathrm{C} 1$ y $\mathrm{C} 2$.

Son dos las dificultades fundamentales que pueden ofrecer estas oraciones. En primer lugar, debido a que en muchos casos durante la instrucción se presenta la primera estructura que se estudia (Si tuviera tiempo, te ayudaría) como modélica y los alumnos la aprenden como fija e inalterable, puede ser que no produzcan o reconozcan las otras, especialmente, las que incluyen formas de indicativo, con usos marcados pragmáticamente, como en (36). Incluso, a pesar de que en los niveles más avanzados se trabajen estas oraciones, los estudiantes tenderán a evitarlas puesto que, por un lado, se sienten más cómodos con el uso de modelos sintácticos fijos y, por otro, puede que no sean capaces de percibir los distintos valores semánticos y pragmáticos de las diferentes estructuras. La aparición de la perífrasis verbal "llegar $a$ + infinitivo" en algunas de estas condicionales, como en (38), que no reproducen el modelo, añade otro factor de complejidad pues el aprendiente debe estar, además, familiarizado con el uso de estas perífrasis.

En segundo lugar, es posible que por transferencia del serbio, en la prótasis usen un condicional en lugar del pretérito imperfecto de subjuntivo (interferencia del esquema de la oraciones introducidas por kad) o un presente, probablemente de subjuntivo (interferencia de las estructuras con $d a$ ).

Por otro lado, el hecho de que kad sea en serbio básicamente una conjunción temporal y en su uso, a veces, se confundan los valores temporales con los condicionales puede llevar a algunos aprendientes de español a usar cuando como nexo condicional. 


\subsubsection{Irreales (condiciones que no fueron reales en el pasado)}

39) Si hubieras llegado antes, habrías visto algo increíble.

Da si stigao ranije, video bi nešto neverovatno.

[Prót.: $D a+$ perf. / Apód.: cond. I]

40) Si Colón no hubiera descubierto América, no conoceríamos el chocolate.

Da Kolumbo nije otkrio Ameriku, ne bismo znali za čokoladu.

[Prót.: $D a+$ perf. / Apód.: cond. I]

41) Si lo sé, no te digo nada, porque... ivaya genio que se te ha puesto!

Da sam znao, ne bih ti ništa rekao, jer... ikako si poludeo!

[Prót.: $D a+$ perf. / Apód.: cond. I]

42) Si llego a verle haciendo eso, imenuda paliza le había dado!

Da sam ga video kako to radi, idobro bih ga istukao!

[Prót.: Da + perf. / Apód.: cond. I]

43) Si estuvieras más atento en clase, lo habrías entendido.

Da si pažljiviij, razumeo bi.

Prót.: $D a+$ perf. / Apód.: cond. I]

Las oraciones condicionales con la estructura de los ejemplos (39) y (40) aparecen en el inventario del PCIC en el nivel B2; las demás se presentan en los niveles superiores, lo cual es un índice de su mayor complejidad.

Es muy posible que los aprendientes solo identifiquen el modelo de "si + pretérito pluscuamperfecto de subjuntivo / condicional compuesto", que es el que se estudia como prototipo, con lo que nos encontraríamos ante errores derivados de su aprendizaje. No obstante, la reproducción de este esquema también puede relacionarse con la transferencia de la L1 puesto que en serbio la combinación de las formas verbales en este tipo de condicionales es siempre la misma (perfecto en la prótasis y condicional en la apódosis).

La adecuada interpretación de las oraciones con presente de indicativo, del tipo (41), puede resultar ardua, sino imposible, ya que el modelo sintáctico no contiene las formas verbales esperadas y las que contiene están aparentemente orientadas hacia el presente, cuando en realidad se refieren al pasado. La aparición de algunas formas verbales en pasado en 
PREVISIÓN DE ERRORES DE SERBIOHABLANTES EN ORACIONES CONDICIONALES Y CONCESIVAS...

el co-texto cercano, como en el caso de (41) y la atención al contexto pueden ayudar en su interpretación. De la misma manera, en la producción es probable que los aprendientes eviten esta estructura y tiendan a usar construcción como la del ejemplo (39).

También pueden producirse confusiones entre las estructuras potenciales y las irreales, sobre todo, cuando las referencias temporales no son muy claras. El hecho de que los valores del potencial II hayan sido asumidos por el potencial I en serbio puede entorpecer la percepción de la distinción entre condicional simple y compuesto en español y puede producir tanto errores de comprensión como de producción.

\subsubsection{Otras formas de expresar condición ${ }^{21}$}

\subsubsection{Prótasis con de + infinitivo}

44) De venir, me avisaría.

Da dolazi, javio bi mi.

[Prót.: $D a+$ pres. / Apód.: cond. I]

45) De haberlo sabido, habría venido antes.

Da sam znala, došla bih ranije.

[Prót.: $D a+$ perf. / Apód.: cond. I]

El PCIC presenta esta construcción en el inventario del nivel C2, lo que puede indicar que solo los aprendientes con un nivel de maestría no cometerán errores aquí, ya que si no han estudiado esta estructura explícitamente es casi imposible que la identifiquen como condicional, dado que en serbio no existe ninguna construcción similar. Como puede verse en la traducción propuesta, la forma verbal debe ser necesariamente finita (presente para el caso del infinitivo simple y perfecto para el infinitivo perfecto) por lo que es posible que utilicen formas conjugadas del verbo, el pretérito imperfecto o el pluscuamperfecto de subjuntivo, en función de si el verbo de la apódosis es un condicional simple o compuesto, lo que les conduciría a repetir los esquemas prototípicos de las potenciales y de las irreales, del tipo (33) y (39).

Además, los estudiantes tendrán mayores dificultades en la interpretación y uso del infinitivo compuesto que del simple. En primer lugar,

21 Como ya se ha señalado, la lista de estructuras que se recogen en este apartado no es exhaustiva, sino selectiva. 
porque en serbio hay un solo infinitivo, simple, y, en segundo, porque durante el aprendizaje se presta escasa atención a las formas verbales no finitas compuestas.

Por otro lado, tampoco se debe olvidar la posible alternancia del infinitivo compuesto y del infinitivo simple en contextos claramente retrospectivos (RAE 2009: 1977-1978), como (46) y (47), lo que favorece la neutralización de sus valores y puede influir en la tendencia al uso genérico del infinitivo simple $y$, en consecuencia, a la formación de periodos potenciales, con condicional simple, en lugar de irreales, con condicional compuesto.

46) De estar en Madrid la semana pasada, me habría llamado.

47) De haber estado en Madrid la semana pasada, me habría llamado.

\subsubsection{Prótasis con gerundio}

48) Conduciendo más deprisa llegaremos antes.

Ako vozimo brže, stići ćemo ranije.

[Prót.: Ako + pres. / Apód.: fut. I]

Esta construcción aparece en el nivel C1 del $P C I C$ y, como la anterior, no tiene ningún equivalente estructural en serbio ${ }^{22}$; por tanto, si no se ha estudiado explícitamente es imposible que la identifiquen como condicional. Así pues, es de esperar que en situaciones de producción libre no se utilice esta estructura y en pruebas de producción controlada se usen formas verbales conjugadas en lugar del gerundio. El no reconocimiento de ese gerundio como prótasis condicional puede crear también problemas en la selección del verbo de la apódosis al no haber ningún indicador formal ni del tipo de condición que expresa la prótasis, ni del tiempo al que se refiere.

\subsubsection{Prótasis que expresan una condición imprescindible}

49) Te lo doy con tal de que/con la condición de que me lo devuelvas mañana.

Dajem ti to pod uslovom da mi vratiš sutra.

[Apód.: pres. / Prót.: pod uslovom da + pres.]

22 En algunos casos muy concretos algunos verbos en gerundio pueden aportar un matiz condicional (aunque también modal) como por ejemplo en Radeći pošteno imaćeš čistu savest'Trabajando honestamente tendrás la conciencia limpia', pero no se puede considerar una estructura condicional. 
PREVISIÓN DE ERRORES DE SERBIOHABLANTES EN ORACIONES CONDICIONALES Y CONCESIVAS...

50) Te lo compraré siempre y cuando apruebes el examen.

Kupiću ti to ukoliko budeš položio/položiš ispit.

[Apód.: fut. I / Prót.: ukoliko + fut. II o pres. ]

Estos nexos de condición imprescindible se mencionan en el PCIC en el nivel B2. Algunos de ellos pueden ser fácilmente identificados por los aprendientes ya que existen equivalentes en serbio, como es el caso de pod uslovom da (literalmente 'bajo condición que') para a condición de (que). Sin embargo, otros, si se atiende solo a su formación, pueden orientar hacia una interpretación temporal en lugar de condicional (siempre que, siempre y cuando) o modal (con tal de que). En la producción, los estudiantes tenderán a evitar nexos formalmente complejos y semánticamente poco transparentes.

En cuanto a las formas verbales, pueden producirse errores de selección del modo verbal, dado que estas locuciones requieren una forma verbal en subjuntivo, de selección del tiempo verbal, especialmente si se refiere al pasado y, por último, de concordancia verbal, ya que ésta no se requiere en serbio.

\subsubsection{Prótasis que expresan una condición negativa}

51) Tardaremos tres horas, a no ser que haya atasco.

Trebaće nam tri sata, osim/sem ako bude gužva.

[Apód.: fut. I / Prót.: osim/sem ako + pres.]

51) Tardaremos tres horas, excepto si hay atasco.

Trebaće nam tri sata, osim/sem ako bude gužva.

[Apód.: fut. I / Prót.: osim/sem ako + pres.]

El PCIC recoge estas oraciones condicionales con salvo si, excepto si, a no ser que y salvo que en el nivel $\mathrm{B} 2$ y menos si, a menos que y excepto que en el $\mathrm{C} 1$.

Los errores más previsibles están relacionados con la selección del modo verbal y de la conjunción presente en estos nexos, puesto que son semánticamente idénticos pero exigen modos distintos en función de la conjunción.

Por otro lado, teniendo en cuenta la equivalencia casi literal entre el español y el serbio en el caso de excepto si/que y osim/sem da/ako, en 
la producción libre los aprendientes tenderán a su uso exclusivo de estos nexos y evitarán otros más complejos y menos familiares como a no ser que.

\subsubsection{Prótasis que expresan una condición remota}

53) En caso de que le veas; dile que me llame.

U slučaju da ga vidiš/budeš video, kaži mu da me nazove.

[Prót.: U slučaju da + pres. o fut. II / Apód.: imp. ]

Los nexos que introducen una condición que se presenta como remota figuran en el nivel $\mathrm{C} 1$ del $P C I C$.

Estos nexos no ofrecen ninguna dificultad para su interpretación, ya que el sustantivo slučaj 'caso' forma locuciones conjuntivas en serbio equivalentes a las del español: u slučaju da ('en caso que'). El obstáculo lo presenta su forma con varias preposiciones y con la opción de que el sustantivo vaya o no determinado con un artículo en en el caso de que. Así, en la producción es posible que se tienda a simplificar en en caso que.

Por lo que se refiere a las formas verbales, en este nivel de dominio, no es previsible que se produzcan errores debido a las restricciones que impone el uso los nexos con formas conjugadas o con infinitivo (o sustantivos, en caso de duda). Como en otros casos, puede haber errores en la selección tanto del modo como del tiempo verbal, sobre todo, en las oraciones orientadas al pasado. En este caso puede también influir negativamente el hecho de que en serbio este nexo suele utilizarse referido casi siempre al presente o al futuro.

\subsection{Oraciones concesivas}

\subsubsection{Prótasis introducidas por aunque}

\subsubsection{Prótasis con aunque + indicativo (factuales)}

54) Aunque tiene mucho dinero, no lo derrocha.

lako ima mnogo para, ne rasipa ih.

23 Una de las mayores dificultades con la que se enfrenta un hablante de serbio al aprender español es el uso y la distribución de los artículos. El serbio carece de artículos y la determinación se marca por otros medios (la flexión casual, la forma determinada e indeterminada de algunos adjetivos, etc.). Los errores en esta área siguen apareciendo incluso en aprendientes expertos con competencia cuasi nativa en español. 
PREVISIÓN DE ERRORES DE SERBIOHABLANTES EN ORACIONES CONDICIONALES Y CONCESIVAS...

[Prót.: lako + pres. / Apód: pres.]

55) Se perdió aunque sabía el camino.

Zalutao je iako je znao put.

[Apód.: perf. / Prtó.: iako + perf.]

56) Aunque estaba enfermo, fue a la escuela.

Mada/lako je bio bolestan, otišao je u školu.

[Prót.: Mada/lako + perf. / Apód.: perf.]

57) Aunque le veré mañana, no le diré nada

lako ću ga videti sutra, necú mu ništa reći.

[Prót.: iako + fut.l / Apód.: fut. I]

58) Aunque hacía sol, sin embargo hacía frío.

lako/Mada/Premda je sijalo sunce, ipak je bilo hladno.

[Prót.: Mada/lako/Premda + perf. / Apód.: perf.]

Las oraciones introducidas por aunque factuales con indicativo son las primeras concesivas que se trabajan en el aula y, según el $P C I C$ corresponden al nivel B1; en niveles posteriores se siguen presentando estas oraciones, fundamentalmente en oposición a los contextos en los que alternan el indicativo y el subjuntivo, destacando las distintas posibilidades expresivas de ambas estructuras (factuales e hipotéticas).

La posible alternancia de modo en las prótasis introducidas por aunque, y las diferencias semánticas que implica, es una de las mayores áreas de dificultad de las concesivas. Por ello, pueden darse errores de comprensión cuando los aprendientes no identifiquen adecuadamente el tipo de información que ofrece la prótasis y errores de producción al presentarla, que se manifestarán en una incorrecta selección del modo verbal.

Los errores por una falsa elección de los tiempos, especialmente los de pasado, también serán muy frecuentes, ya que caracterizan las producciones de los estudiantes y pueden confluir con los de modo.

En cuanto a los nexos, en algunos casos, pueden usar y si o y cuando en lugar de aunque, ya que esta es la traducción literal de iako e i kad en oraciones referidas al presente o futuro.

\subsubsection{Prótasis con aunque + subjuntivo (hipotéticas, factuales y contrafactuales)}

59) Aunque venga mi madre, no la verás.

lako dođe/ $\underline{\text { bude došla moja majka, nećeš je videti. }}$ 
[Prót.: lako + pres. / fut. II / Apód.: fut. I] la verás'

Con la interpretación de 'Aunque venga, no sé si va a venir o no, no

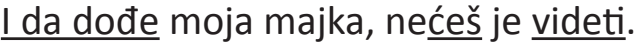

[Prót.: / da + pres. / Apód.: fut. I]

Con la interpretación de 'Aunque venga, seguramente no va a venir, no la verás'.

60) Aunque lloviera, iríamos de excursión.

I kad bi padala kiša, išli bismo na izlet.

[Prót.: I kad + cond. I / Apód.: cond. I]

61) Aunque hubieras querido ayudarme, no habrías podido.

I da si hteo da mi pomogneš, ne bi mogao.

[Prót.: I da + perf. / Apód.: cond. I]

62) - Me ha dicho que vaya.

- Aunque te lo haya dicho, no vayas.

- Rekao mi je da idem.

- Neka ti je i rekao, nemoj da ideš.

[Prót.: Neka i + perf. / Apód.: imp.]

Las oraciones concesivas con subjuntivo aparecen en los inventarios de los niveles B2, C1 y C2. Como ya se ha mencionado, el gran problema es que con el subjuntivo se puede presentar, tanto información hipotética como factual y ello tiene consecuencias formales y semántico-pragmáticas.

Estas estructuras ofrecen la misma dificultad en la selección del modo que las anteriores. También pueden producirse algunos errores en la elección del tiempo: en las oraciones orientadas al futuro (con imperfecto de subjuntivo) puede aparecer el condicional; en las oraciones orientadas al de pasado (con pluscuamperfecto de subjuntivo) es probable el uso del condicional compuesto o de un tiempo de pasado de indicativo. La confusión de las oraciones con imperfecto y con pluscuamperfecto de subjuntivo puede darse debido a una interpretación errónea de las referencias temporales implicadas en la concesión.

Son particularmente confusas las oraciones concesivas factuales con subjuntivo, es decir, aquellas en las que se presenta una información 
PREVISIÓN DE ERRORES DE SERBIOHABLANTES EN ORACIONES CONDICIONALES Y CONCESIVAS...

confirmada y compartida en las que se usa el ya mencionado subjuntivo polémico (como en 62), ya que los aprendientes de ELE tienden a asociar el uso del subjuntivo con la noción de hipótesis y el del indicativo con la de realidad o confirmación. En estas oraciones, los serbiohablantes seleccionarán casi siempre una forma verbal en indicativo, en lugar de en subjuntivo y, en compresión, interpretarán la información como nueva.

Como en el caso de las condicionales, dado que durante la instrucción se suele incidir especialmente en el aprendizaje de tres modelos ${ }^{24}$ (Aunque venga, no la verás; Aunque viniera, no la verías; Aunque hubieras venido, no la habrías visto), los estudiantes tenderán a reproducir sistemáticamente estas estructuras.

\subsubsection{Otras construcciones concesivas}

\subsubsection{Prótasis focalizadas}

63) Aun teniendo el viento en contra, consiguió llegar en media hora.

Čak i s vetrom u grudi, uspeo je da stigne za pola sata.

[Čak $i+$ instrumental / perf.]'Incluso con el viento en contra,...'

64) Aun cuando necesitaba ayuda, nunca nos la pidió.

Čak i kad mu je trebala pomoć, nikad nam je nije tražio.

[Prót.: Čak i kad + perf. / Apód.: perf.]

65) Incluso (si está) enferma, va a trabajar.

Čak i (kad/ako je) bolesna, ide na posao.

[Prót.: Čak i (kad/ako) + perf. / Apód.: perf.]

El PCIC presenta las oraciones con incluso si con indicativo, como concesivas impropias no factuales escalares, en el nivel B1 y los conectores aun si, aun cuando, incluso cuando, con indicativo y subjuntivo, como introductores de prótasis factuales y no factuales en el nivel C1.

En el caso de las oraciones con gerundio, puesto que no hay en serbio ninguna estructura concesiva similar, si no se han estudiado explícitamente, ni las interpretarán correctamente ni serán capaces de seleccionar las formas verbales adecuadas. Puede ocurrir que, en la producción,

24 También en el estudio de la gramática de su propia lengua se presentan unos modelos más o menos equivalentes, lo que también les hace estar familiarizados con esos esquemas. 
en lugar del gerundio utilicen una forma conjugada o incluso un complemento circunstancial (instrumental), como el que aparece en la traducción serbia que hemos propuesto para (63).

Los problemas con las formas verbales se manifestarán tanto en la selección de los tiempos verbales como de los modos en la prótasis y de la apódosis. Además las restricciones que impone la presencia de si en estos conectores pueden provocar más errores, ya que si rechaza tanto el futuro de indicativo, como el presente y el pretérito perfecto de subjuntivo.

Los estudiantes tenderán a usar como nexos aquellos con los que están más familiarizados, como aunque, o los que tienen una equivalencia en serbio clara como y cuando (i kad), incluso (čak i) o incluso cuando (čak i kad).

\subsubsection{Prótasis con construcciones preposicionales}

\subsection{Locuciones con cuantificadores introducidas por por}

66) Por más que trabajó, no logró terminar a tiempo.

Koliko god da je radio, nije uspeo de završi na vreme.

[Prót.: Koliko god + perf. / Apód.: perf.]

67) Por más que trabaje, no logrará terminar a tiempo.

I da /mnogo radi, neće uspeti de završi na vreme.

[Prót.: I da+ perf. / Apód.: fut. I]

68) Por mucho que estudia, no aprueba.

lako mnogo uči, ne polaže.

[Prót.: iako + perf. / Apód.: perf.]

69) Por mucho que estudie, nunca aprobará.

Koliko god bude učio/da uči, nikad neće položiti.

[Prót.: Koliko god + fut. II / da + pres. / Apód.: fut. I]

70) Por muy orgulloso que sea, tendrá que trabajar como los demás.

Koliko god daje ponosan, moraće da radi kao i ostali.

[Pró.: Koliko god da + pres. / Apó.: fut. I]

71) Por mucha gente que le ayude, nunca va a conseguir tanto dinero. Koliko god da mu ljudi pomognu, nikad neće uspeti da skupi toliko para.

[Prót.: Koliko god da + pres. / Apód.: fut. I]

Por más, por mucho/poco, por muchos/muchas, por pocos/pocas aparecen en el inventario del nivel B2 delPCIC para la formación de concesivas, tanto con indicativo como con subjuntivo. 
PREVISIÓN DE ERRORES DE SERBIOHABLANTES EN ORACIONES CONDICIONALES Y CONCESIVAS...

Los errores relacionados con los nexos de estas oraciones se deben a dos cuestiones diferentes. Por un lado, a su complejidad formal: admiten distintos cuantificadores (mucho, muy, poco y más: por más, por muy, por mucho/poco que, por muchos/as, por pocos/as), los términos cuantificados pueden ser también de diferente naturaleza (nombres, adjetivos, adverbios y verbos), la conjunción subordinante que es obligatoria $y$, además, pueden usarse tanto formas de indicativo como de subjuntivo en función de cómo se presente la información. Por otro, mientras que cuando estos nexos se combinan con formas verbales en subjuntivo para introducir prótasis hipotéticas tienen un equivalente en serbio fácilmente identificable (koliko god da), cuando introducen prótasis factuales con indicativo pueden equivaler a las estructuras con koliko god da o con iako, según el contexto. Esto puede llevar a los estudiantes a evitar el uso de estas locuciones formalmente complicadas o a generalizar su uso con subjuntivo y, en la comprensión, a interpretarlas incorrectamente ya que tenderán a considerarlas siempre hipotéticas.

El hecho de que el cuantificador pueda eludirse en algunos contextos puede impedir que los aprendientes perciban el valor concesivo e interpreten estas prótasis como causales en casos como Por absurdo que sea, no voy a dejarlo.

La selección de las formas verbales, como en el resto de las concesivas, puede provocar errores tanto de modo como tiempo.

\subsection{Locuciones introducidas por con}

72) Con lo que trabaja y apenas gana nada.

Toliko radi, a jedva nešto zaradi

[Prót.: Toliko + pres. / Apód.: ajedva+ pres.]

73) Con lo mucho que trabaja y lo poco que gana

Tako mnogo radi, a tako malo zaradjuje.

[Prót.: Tako mnogo + pres. / Apód.: a tako + pres.]

74) Con la de amigos que tiene y nadie le ayuda

Ima tolike prijatelje, a niko da joj pomogne.

[Prót.: Toliko Sintagma Nominal+ pres. / Apód.: aniko + pres.]

75) Con el frío que hace y va sin abrigo.

Tako/toliko je hladno, a on ide bez kaputa.

[Prót.: Toliko/tako Sintagma Adjetivo+ pres. / Apód.: $a+$ pres.] 
En el nivel $C 1$ del $P C I C$ se describen como concesivas impropias ponderativas las introducidas por con lo que con indicativo y se mencionan los nexos (con) el / la / la de como intensivos.

De la misma manera que en las introducidas por por, la composición de estos nexos puede producir muchos errores debido a la variedad de elementos que los integran. Por otra parte, teniendo en cuenta que el uso de los artículos es una de las áreas en las que más errores producen los serbiohablantes, la necesaria presencia de un artículo determinado en estos nexos añade otra dificultad. La obligatoriedad de la conjunción que en estas estructuras también puede favorecer el error, ya que en serbio no es necesaria una conjunción en estos casos. En general, los aprendientes tenderán a evitar el uso de estos conectores.

En cuanto a las formas verbales, estas estructuras no deberían representar un problema para la selección del modo verbal, al rechazar el subjuntivo, pero pueden surgir errores en selección del tiempo verbal, especialmente si se refieren al pasado.

Tanto en la comprensión como en la producción podrían producirse errores debidos a las similitudes y diferencias entre las estructuras introducidas por por y con.

\subsubsection{Fórmulas concesivas duplicadas}

76) Pase lo que pase, siempre estaré a tu lado.

Šta god da bude, uvek ću biti uz tebe.

[Prót.: Šta god da + pres. / Apód.: fut. I]

77) No me pases llamadas, sea quien sea la persona que llame.

Nemoj da mi daješ vezu, ko god daje osoba koja me zove.

[Apód.: imp. / Prót.: ko god da + pres.]

78) Digan lo que digan tus compañeros, no les creas.

Šta god da ti kažu kolege, nemoj da im veruješ.

[Prót.: Šta god da + pres. / Apód.: imp.]

Bilo šta da ti kažu, nemoj da im veruješ.

[Prót.: Bilo šta da + pres. / Apód.: imp.]

Las concesivas con duplicación del verbo en subjuntivo se presentan en el nivel C1 del PCIC. 
PREVISIÓN DE ERRORES DE SERBIOHABLANTES EN ORACIONES CONDICIONALES Y CONCESIVAS...

Dada la equivalencia formal con algunas estructuras en serbio y que sus usos son claramente identificables con algunos de los valores del subjuntivo que se estudian en niveles inferiores, esta estructura resulta de fácil comprensión e, incluso, producción, especialmente, cuando se usan en presente. Así, los problemas pueden aparecer la oración ser refiere al pasado, lo cual puede dar lugar a la evitación de la estructura o a una errónea selección de la forma verbal.

\section{Implicaciones didácticas}

Considerando el contraste y la previsión de errores que se han realizado, para favorecer el proceso de aprendizaje y tratar, en la medida de lo posible, de superar las áreas de dificultad, la instrucción formal en el aula de ELE de aprendientes autónomos y competentes serbiohablantes debe tener presentes las siguientes cuestiones:

1. En los materiales utilizados en el aula se debe abandonar la simplificación metodológica en favor de descripciones más precisas y ricas en variedad de estructuras;

2. En cuanto al uso de los tiempos verbales, se deben enriquecer los valores de cada uno de ellos en lugar de describirlos sucintamente. En muchos casos la oposición entre los tiempos de pasado se establece apoyándose en dicotomías como durativo/ puntual, terminado/no terminado, etc. y en ejemplos con marcadores temporales explícitos, cuyo contexto es únicamente la oración. Fuera del aula y de los manuales y de las gramáticas, la situación es bien distinta, pues las referencias temporales no siempre son explícitas y son el contexto y/o ciertos conocimientos implícitos sobre el tema o sobre la situación comunicativa los que nos proporcionan la información temporal necesaria y los que exigen un determinado tiempo;

3. En el trabajo en el aula es necesario fragmentar el sistema de la lengua para poder avanzar en el aprendizaje. Sin embargo, en pocas ocasiones se trata de reunir esa sucesión de fragmentos 
para formar de nuevo el sistema y eso provoca que el estudiante no sea capaz de interrelacionar unos con otros. Es frecuente que cuando se avanza en el estudio de la oraciones complejas se concentre toda la atención en los esquemas sintácticos de cada uno de los tipos y se abandonen cuestiones que no son exclusivas de ellos o que se consideran ya superadas, como los valores y usos de los tiempos verbales o la dicotomía ser/estar. Durante la instrucción en estos niveles de dominio se debe incidir explícitamente en la relación que mantienen todos los elementos que participan de cualquier acto de comunicación;

4. Debe abandonarse el trabajo exclusivo con ejemplos descontextualizados que carecen de información suficiente para que el alumno comprenda determinadas diferencias (por ejemplo, el uso del indicativo y del subjuntivo en concesivas cuyo nexo permite formalmente el uso ambos modos, pero que no expresan lo mismo) o con oraciones con marcadores explícitos (por ejemplo, en el uso del imperfecto y del indefinido de indicativo), ya que fuera del aula mucha información relevante no es explícita o no forma parte de la estructura oracional. El trabajo con textos, y no con oraciones aisladas, y la ejemplificación de relaciones semánticas y sintácticas complejas ayudarán al estudiante a valorar todos los factores que componen un texto y a superar los esquemas oracionales;

5. Debe favorecerse el uso de materiales y actividades que acerquen al estudiante a situaciones reales de comunicación, en las que los elementos pragmáticos adquieren gran importancia, para que se acostumbre a valorar la información que estos ofrecen y que es fundamental para la comunicación, en general, y para la adecuada interpretación de las oraciones condicionales y concesivas, en particular;

6. El conocimiento de la lengua materna de los estudiantes por parte del profesor o la utilización de materiales dirigidos a estudiantes de una determinada lengua puede ser de gran utilidad para fomentar la reflexión sobre las lenguas y las diferentes formas de expresión y para entender algunas cuestiones, así 
PREVISIÓN DE ERRORES DE SERBIOHABLANTES EN ORACIONES CONDICIONALES Y CONCESIVAS...

como para evitar explicaciones innecesarias. El caso del uso del subjuntivo en español podría ser un ejemplo de ello ya que los alumnos concentran todo su esfuerzo en aprender determinadas reglas de uso sin reparar en que muchas de las diferencias semánticas expresadas por la dicotomía indicativo/subjuntivo se expresan también en serbio, pero por otros medios o, dicho de otra forma, que la expresión de la modalidad no está ligada exclusivamente al subjuntivo. La reflexión sobre este tema sería de gran ayuda para la identificación y el uso de las oraciones condicionales y concesivas en español y, por supuesto, para otras estructuras;

7. Por último, la motivación debe ser uno de los motores principales del aprendizaje. Por ello, en el aula debe crearse la necesidad de que los alumnos usen el español de todas las formas posibles, en actividades comunicativas, formales, de producción, de comprensión, orales, escritas, individuales, colectivas..., que permitan comprobar la utilidad de las mismas y su reflejo en el dominio de la lengua, lo cual impulsará el deseo de perseverar en su aprendizaje.

\section{Conclusiones}

Dado que queda fuera del objetivo de este trabajo, no se han descrito las oraciones condicionales y concesivas en español; sin embargo, hay que destacar que el conocimiento de las restricciones sintácticas y de los valores expresivos de estas oraciones es un paso previo imprescindible para poder enseñarlas en el aula de ELE y comprender la actuación de los aprendientes cuando tratan de usarlas o de interpretarlas.

La descripción de las estas oraciones en serbio, lejos de pretender presentar un análisis en profundidad de las mismas, se ha planteado con el objeto de observar similitudes y diferencias que puedan ayudar a detectar áreas de dificultad en el aprendizaje de ELE. Para ello, se han comparado las oraciones en las dos lenguas, tomando como punto de partida algunas oraciones en español y proponiendo su traducción en serbio, junto con su esquema sintáctico orientativo para los no hablantes de serbio. 
Este contraste entre las construcciones condicionales y concesivas en español y en serbio nos permite prever que algunos de los errores se deberán a la transferencia negativa del serbio, pero también que algunos de los aciertos están relacionados con la transferencia positiva. Asimismo, hemos podido observar que, independientemente, de la lengua materna de los aprendientes, la complejidad de algunas de las estructuras en español también puede ser la fuente del error.

En general, si los aprendientes han superado el nivel B2, el índice de acierto en la producción de estas oraciones debe ser más alto que el de error, y en los que hayan superado los niveles C1 y C2 la incidencia del error debería ser muy baja. Para la explicación de los errores en estos niveles habrá que tener en cuenta no solo las dificultades relacionadas con las construcciones condicionales y concesivas, sino las generales en el uso del español. Además, será necesario observar detenidamente el contexto en el que aparece ya que quizá sea un elemento específico el haya inducido el error.

Por ello, la comparación de estas oraciones nos lleva a proponer que algunos errores serán propios de determinadas estructuras, mientras que otros podrán aparecer siempre que se use el español. Así, los errores relacionados con las formas verbales se manifestarán en todos los niveles de uso de la lengua, aunque algunos pueden tener mayor incidencia en determinados contextos. Los problemas con la selección de los tiempos verbales surgirán especialmente en situaciones no referidas al presente y los de selección del modo en aquellas en las que es posible una alternancia de los dos. Por tanto, en las oraciones que hemos presentado, los errores de tiempo afectarán de la misma manera a condicionales y concesivas, mientras que los de modo serán más numerosos en las concesivas.

En cuanto al uso de los nexos y las distintas formas de expresar condición y concesión, se ha sugerido que los aprendientes usarán e interpretarán adecuadamente los más frecuentes (si y aunque) y los que tienen un equivalente semántico y formal claro en serbio (con la condición de que, en el caso de que, pase lo que pase, etc.), mientras que encontrarán dificultades en la producción y en la comprensión de otros menos transparentes semánticamente o más complejos formalmente (uso del gerundio con valor condicional o concesivo, con lo que, por mucho que, etc.).

Por último, si observamos la estructura oracional en conjunto, suponemos que el índice de error será muy bajo en aquellas oraciones que reproducen los esquemas típicos, es decir, introducidas por si o aunque y 
PREVISIÓN DE ERRORES DE SERBIOHABLANTES EN ORACIONES CONDICIONALES Y CONCESIVAS...

con una correlación de tiempos del tipo: Si puedo, voy; si pudiera, iría; Si hubiera podido, habría ido; Aunque venga, no la verás; Aunque viniera, no la verías; Aunque hubiera venido, no la habrías visto. Por el contrario, en las que se varían estos esquemas, ya sea por los nexos, por la correlación de las formas verbales, por la incorporación o elisión de algún elemento en el esquema binario de prótasis-apódosis, surgirán más errores.

Teniendo en cuenta todos estos hechos, en el aula se debe dirigir la atención hacia las áreas de dificultad específicas e implementar actividades que sirvan para superar los errores. En este sentido, para el aprendizaje de estas oraciones es imprescindible destacar la importancia del contexto, de las implicaciones subyacentes, de las referencias temporales y de las posibles relaciones que pueden establecerse dentro y fuera de la estructura sintáctica. Por ello, en el aula debe evitarse el trabajo exclusivo con estructuras sintácticas fijas y descontextualizadas y debe atenderse a la gran variedad de significados que pueden transmitirse, también mediante una gran variedad de formas.

\section{BIBLIOGRAFÍA}

Alonso Raya, Rosario et al. Gramática básica del estudiante de español. Barcelona: Difusión, 2011. Impreso.

Alonso Zarza, María Ángeles. Análisis de errores en oraciones condicionales y concesivas en aprendientes de ELE serbiohablantes. Madrid: Tesis Doctoral Universidad Autónoma de Madrid, 2015.

Amenós Pons, José et al. "Gramática y pragmática en la adquisición de ELE: la alternancia modal en las estructuras condicionales". Jacinto González Cobas et al. (eds.) ¿Qué necesitamos en el aula de ELE?: reflexiones en torno a la teoría y la práctica RedELE, Volúmen monográfico (2014): 17-55. Web. 30.07.2016.

http://www.mecd.gob.es/dctm/redele/Material-RedEle/ Numeros\%20Especiales/libro-completouam.pdf?documentl$\mathrm{d}=0901 \mathrm{e} 72 \mathrm{~b} 81998729$.

Aragonés, Luis y Ramón Palencia. Gramática de uso del español: teoría y práctica (A1-A2, B1-B2, C1-C2).Madrid: SM, 2009-2010. Impreso.

Barić, Eugenija et al. Priručna gramatika Hrvatskoga književnog jezika. Zagreb: Školska knjiga, 1979. Impreso. 
Bosque, Ignacio y Violeta Demonte (dirs.). Nueva Gramática Descriptiva de la Lengua Española. Madrid: Espasa-Calpe, 1999. Impreso.

Castañeda Castro, Alejandro (coord.). Enseñanza de la gramática avanzada de ELE. Madrid: SGEL, 2014. Impreso.

Coronado González, María Luisaet al. A fondo. Nivel avanzado. Madrid: SGEL, 2003. Impreso.

Coronado González, María Luisa et al. A fondo. Nivel superior. Madrid: SGEL, 2004. Impreso.

Coronado González, María Luisa et al. Materia prima. Madrid: SGEL, 1996. Impreso.

Chamorro Guerrero, María Dolores et al. Abanico. Nueva edición. BarceIona: Difusión, 2010. Impreso.

Chamorro Guerrero, María Dolores et al. El Ventilador. Curso ELE superior. Barcelona: Difusión, 2006. Impreso.

Fernández Molero, María del Carmenet al. (2004), "Las oraciones condicionales en los manuales de ELE: algo más que una condición". Actas del XV Congreso Internacional de ASELE, Málaga, 2004: 946-951. Impreso.

Flamenco García, Luis (1999), "Las construcciones concesivas y adversativas", Ignacio Bosque y Violeta Demonte (dirs.). Nueva Gramática Descriptiva de la Lengua Española. Madrid: Espasa-Calpe, 1999: 3805-3878. Impreso.

García González, Javier y María Ángeles Alonso Zarza."Análisis de errores en español de serbiohablantes", Julijana Vučo et al. (eds).Jezik Struke: Teorija y Praksa. Zbornik radova, Beograd: Univerzitet u Beogradu, 2009. 597-609. Impreso.

García Santos, Juan Felipe.Español. Curso de perfeccionamiento. Salamanca: Ediciones Universidad de Salamanca, 1992. Impreso.

Gómez Torrego, Leonardo. Gramática didáctica del español. Madrid: SM, 2007. Impreso.

Instituto Cervantes. Plan curricular del Instituto Cervantes: Niveles de referencia para el español (3 vols.). Madrid: Instituto Cervantes-Biblioteca Nueva, 2006. Impreso.

Klajn, Ivan. Gramatika srpskog jezika. Beograd: Zavod za udžbenike i nastavna sredstva, 2005. Impreso.

Kovačević, Miloš (ed.). Srpski jezik, književnost, umetnost. Knjiga 1: Srpski jezik u (kon)tekstu. Kragujevac: FILUM, 2008. Impreso.

Krstić, Katarina y TijanaPištignat. "Análisis de errores en el aprendizaje del español por alumnos que tienen como lengua materna el serbio", Colindancias, 4 (2013): 393-404. Web. 30.07.2016. http://colindancias.uvt.ro/index.php/colindancias/article/view/5/2. 
PREVISIÓN DE ERRORES DE SERBIOHABLANTES EN ORACIONES CONDICIONALES Y CONCESIVAS...

López García, Ángel (1999), “Relaciones paratácticas e hipotácticas”, Ignacio Bosque y Violeta Demonte (dirs.). Nueva Gramática Descriptiva de la Lengua Española. Madrid: Espasa-Calpe, 1999. 3507-3549. Impreso.

Llopis-García, Reyes et al. Qué gramática enseñar, qué gramática aprender. Madrid: Edinumen, 2012. Impreso.

Martí Sánchez, Manuel et al. Gramática española por niveles. Madrid: Edinumen, 2009. Impreso.

Matte Bon, Francisco.Gramática comunicativa del español(2 vols.). Madrid: Edelsa, 1995. Impreso.

Montolío, Estrella. “'Si me lo permiten...' Gramática y pragmática: sobre algunas estructuras condicionales regulativas en español". Diálogos Hispánicos, 11 (1993): 119-147. Impreso.

Montolío, Estrella. "Las construcciones condicionales". Ignacio Bosque y Violeta Demonte (dirs.). Nueva Gramática Descriptiva de la Lengua Española. Madrid: Espasa-Calpe, 1999. 3643-3738. Impreso.

Pastor Cesteros, Susana. "De la gramática pragmática a la pragmática en el aula". Didáctica del español como lengua extranjera. Expolingua 1999. MarcoELE, 9 (2009): 221-234. Web. 29.07.2016. http://marcoele.com/descargas/expolingua_1999.pastor.pdf.

Pranjković, Ivo. Druga hrvatska skladnja Sintaktičke rasprave. Zagreb, Hrvatska sveučilišna naklada, 2001. Impreso.

Real Academia Española. Nueva gramática de la lengua española. Madrid: Espasa-Calpe, 2009. Impreso.

Rubinjoni Strugar, Vlatka. "Análisis de los errores de concordancia en la expresión escrita de los aprendientes serbios de ELE", Linred, XI (2014). Web. 28.07.2016.

http://www.linred.es/articulos_pdf/LR_articulo_12042014.pdf.

Santos Gargallo, Isabel. (1994), "Análisis de errores: valoración gramatical y comunicativa en la expresión escrita de estudiantes de ELE". Actas del II Congreso Internacional de ASELE. Málaga, 1994: 169-174. Impreso.

Santos Gargallo, Isabel. Análisis Contrastivo, Análisis de Errores e Interlengua en el marco de la Lingüística Contrastiva. Madrid: Síntesis, 1993. Impreso.

Santos Gargallo, Isabel. La enseñanza de segundas lenguas. Análisis de errores en la expresión escrita de estudiantes de español cuya lengua nativa es el serbiocroata. Madrid: Tesis doctoral Universidad Complutense de Madrid, 1991.

Stanojčić, Živojin y Ljubomir- Popović. Gramatika Srpskoga jezika. Beograd: Z.U.N.S.,1992. Impreso. 
Stevanović, Mihailo. Savremeni Srpskohrvatski jezik. Gramatički sistemi i književnojezika norma. Beograd: Nauka Knjiga, 1989. Impreso.

Vučo, Julijana et al. (eds). Jezik Struke: Teorija y Praksa. Zbornik radova. Beograd: Univerzitet u Beogradu, 2009. Impreso

Zečević Krneta, Gorana."Una aproximación al estudio del corpus de aprendices serbios de E/LE”. Colindancias, 4 (2013): 413-422. Web. 29.07.2016. http://colindancias.uvt.ro/index.php/colindancias/ article/view/34/31.

\title{
María Ángeles Alonso Zarza
}

\section{PREDICTION OF ERRORS OF SERBIAN SPEAKERS IN CONDITIONAL AND CONCESSIVE CLAUSES IN SSL: A CONTRASTIVE APPROACH}

\begin{abstract}
Summary
The contrastive approach to conditional and concessive clauses presented in this paper pursues a clearly didactic objective: identifying the difficulties that SSL Serbianspeaking learners may have in these aspects and seeking their causes in order to help prevent and overcome errors. The contrast between Spanish and Serbian language structures can have direct application in classroom work and the creation of teaching materials, and it should serve to draw attention to the treatment of the problem areas and errors which offer greater resistance. Conditional and concessive clauses in Spanish pose two basic formal difficulties: the use of links (especially those other than si and aunque) and the selection of tenses and verbal modes (verbal referential meanings and co-referentiality of tenses). In addition to these formal issues, we should not forget the semantic and pragmatic problems raised by their implications. This approach to complex structures calls attention to the errors of competent learners which, since they tend not to hinder communication, remain unnoticed, and/or for the overcoming of which specific therapies are not proposed, which may result in fossilization.
\end{abstract}

Keywords: SSL learning, Serbian speakers, conditional and concessive clauses, contrastive analysis, error prediction, implications for teaching. 